\title{
Non-formal Techniques for Early Assessment of Design Ideas for Services
}

\author{
Gerrit C. van der Veer ${ }^{1(\bowtie)}$ and Dhaval Vyas ${ }^{2}$ \\ 1 Open University The Netherlands, Heerlen, The Netherlands \\ gerrit@acm.org \\ 2 Queensland University of Technology, Brisbane, Australia
}

\begin{abstract}
Designing systems for multiple stakeholders requires frequent collaboration with multiple stakeholders from the start. In many cases at least some stakeholders lack a professional habit of formal modeling. We report observations from student design teams as well as two case studies, respectively of a prototype for supporting creative communication to design objects, and of stakeholder-involvement in early design. In all observations and case studies we found that non-formal techniques supported strong collaboration resulting in deep understanding of early design ideas, of their value and of the feasibility of solutions.
\end{abstract}

\section{In Early Stages of User Centered Design Flexibility Is Required}

In user centered product design a strong tradition exists of starting from a task model, subsequently developing a detailed design model (often structured along functionality, dialogue, and representation), model based prototyping and evaluation, ending in formal specifications [6].

However, since increasingly design efforts focus on services (i.e., opportunities which often will be new including the context of use), the stakeholders of the new service are unable to precisely formulate and formalize their needs, ideas, and the context of the envisioned service [8]. Sommerville [4] points to the need of flexible requirements elicitation techniques, both for single user type situations in the phase of feasibility study, and for the current service context: stakeholders often do not know what they need, do not agree, and requirements change during the analysis.

Sommerville's elicitation techniques are viewpoint oriented, but the problem is how to identify future viewpoints. Stakeholders most of the time are not able to be explicit on what they need in relation to a new system that will change the context of use. Moreover, stakeholders often have different roles that result in different points of view on the requirements for a new system. And as soon as the concepts of a new system develop requirements change.

Ethnography alone does not work since any design aims at a new system that will be different from the existing system and which will change the structure of the related community of practice. In addition, we need to consider that not only the requirements but also the context will change through putting the novel services in practice. An obvious solution is the use of scenarios to envision, in collaboration with the stakeholders, how a new system may be used in practice. 
Designers use their professional expertise to apply it on the domain they are designing for. Designers need tools and a design environment, in order to implement their design decisions. If these are not available, designers have to invest in additional types of expertise, or they have to cope with a suboptimal context. And all the time they need to communicate, with their colleagues in a design team and with stakeholders. Visualizing design ideas often is a main challenge. Keeping track of ideas, both for the individual designer and for the team, is another. Finally, when communicating with stakeholders, these need to be supported to understand, as well as to contribute their own ideas too.

That is what the last section of this paper is about. IT supported services are new, and in many cases are meant to be new, stakeholders will only have vague ideas if at all, and mostly have no clue about other stakeholders, about differences in context and culture, nor about relevant functionality and opportunities. The traditional and well grounded tools and techniques are not sufficient for this emerging domain of design.

We will illustrate our observations and emerging approach by providing illustrations from ethnographic studies of design practice in academic design contexts, after which we will discuss two case studies in design education where we were able to introduce some new elements in the situation and to observe and analyze (again, in an ethnographic way) the outcomes, featuring: (1) co-design merging ethnography with rough prototyping; and (2) bootstrapping service design techniques in collaboration with stakeholders.

\section{Ethnographic Impressions of Student Design Practices}

We will first illustrate some observations from a series of ethnographic studies reported in [7] that triggered our interventions in the case studies that will be discussed below. We had the opportunity to observe work in progress in several industrial design studios in polytechnics and to follow projects of design students. Observations 1-5 are from two different Industrial Design Departments in Dutch Polytechnics (in total 6 teams of 3-5 students).

These students worked in teams, as was required by their supervisors, and as seems standard in current industrial design practice. Their teachers did not stress specific design methods or the use of specific tools and techniques. In almost all cases it was the final design and the story told with it that was subject to assessment, quite similar to what clients of design tend to look for.

Our focus was on the process, on the techniques and tools applied and on the artifacts and representations created and used during the process. We detected several phenomena that seem "natural" for (student) design studios, which we like to share:

Observation 1. Exploration Utilizes Multiple Media and Multiple Types of Behavior Students talk, gesture, sketch, and scribble (sometimes most of these at the same time, see Figs. 1 and 2).

\section{Observation 2. The Environment Will Be Dressed to Support}

Our designers develop a creative ecology that they need to get inspired. To a certain extend this is personal and kept kind of private (Fig. 3), but there seem a strong need for a shared environment developed and used as a team (Fig. 4). 


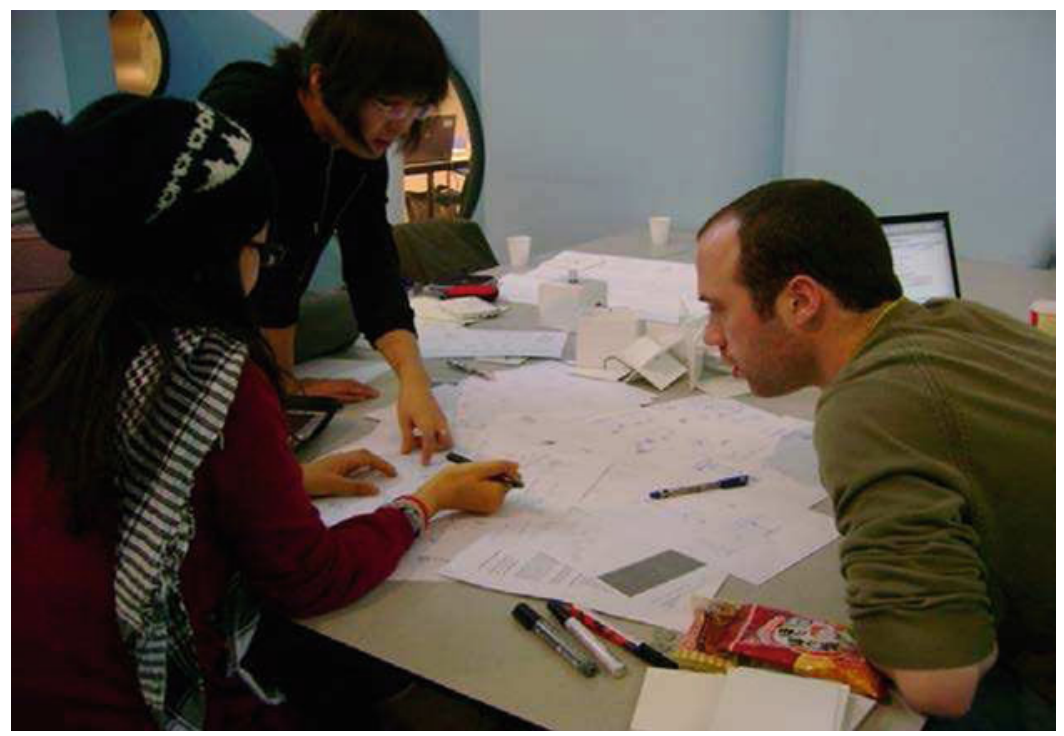

Fig. 1. Communication through a complex of channels

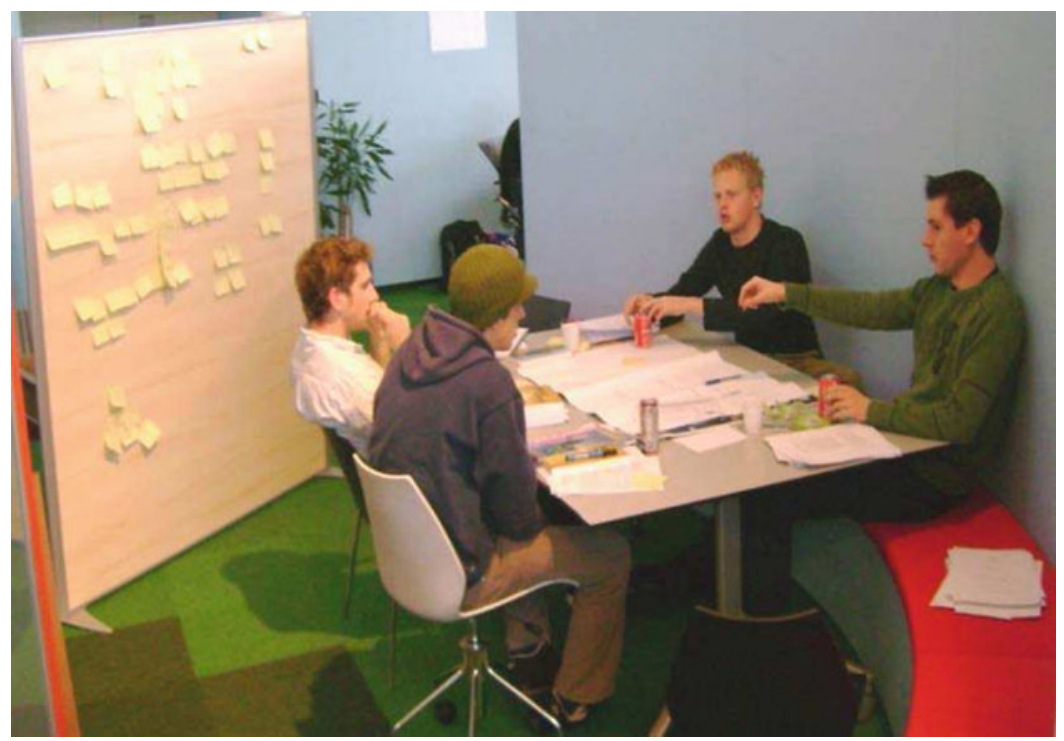

Fig. 2. Communication using artifacts and gestures 


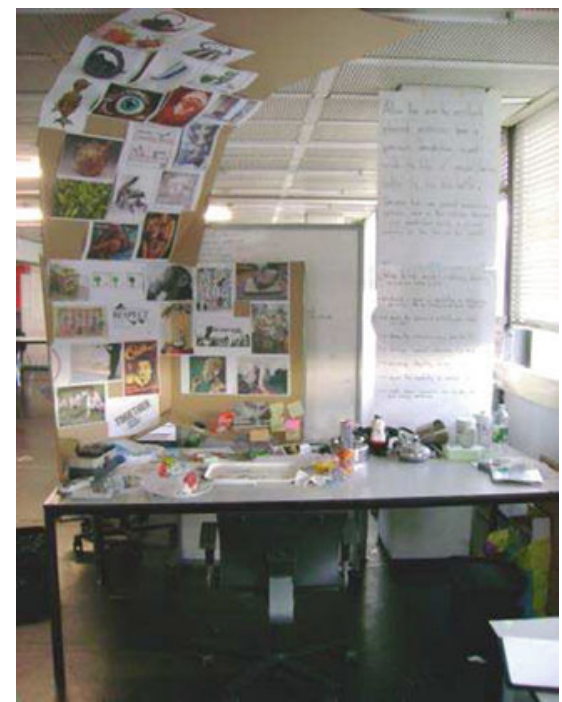

Fig. 3. Private work environment

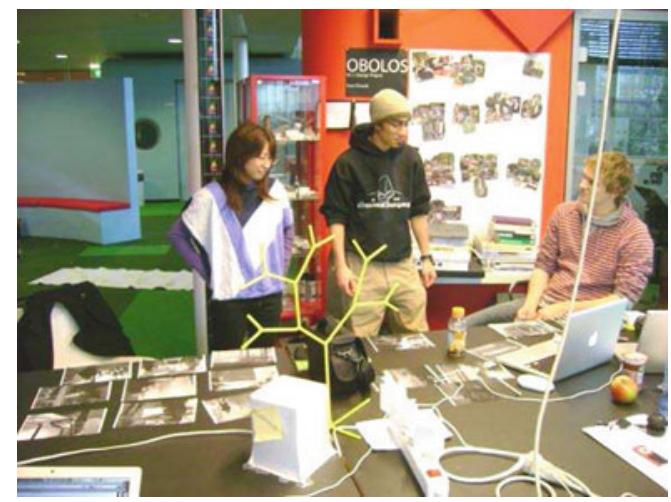

Fig. 4. Shared team design environment

These environments are for "just be inspired" (Fig. 5) or to create artifacts like personas to share understanding (Fig. 6), and they join each other in adding annotations. Ongoing projects required shared awareness of what has been considered (Figs. 7(a) and (b)). The physical space is used to develop structure, to compare and understand development, and to develop and share visions and concepts. 


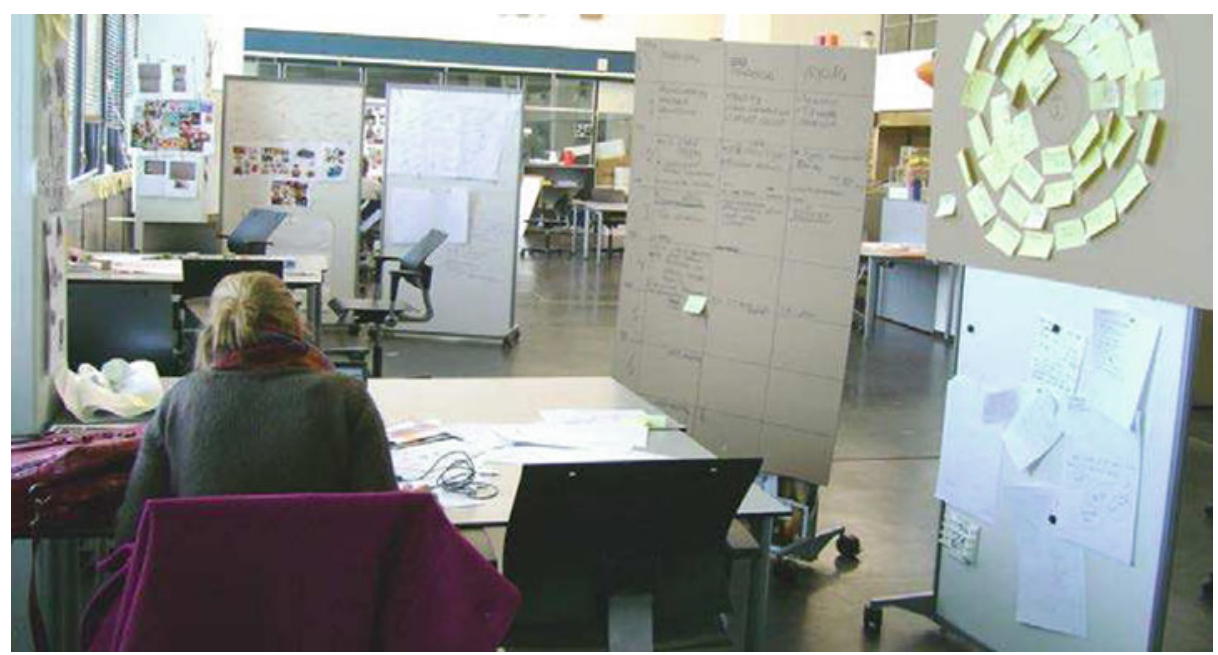

Fig. 5. Elements in the environment considered to inspire

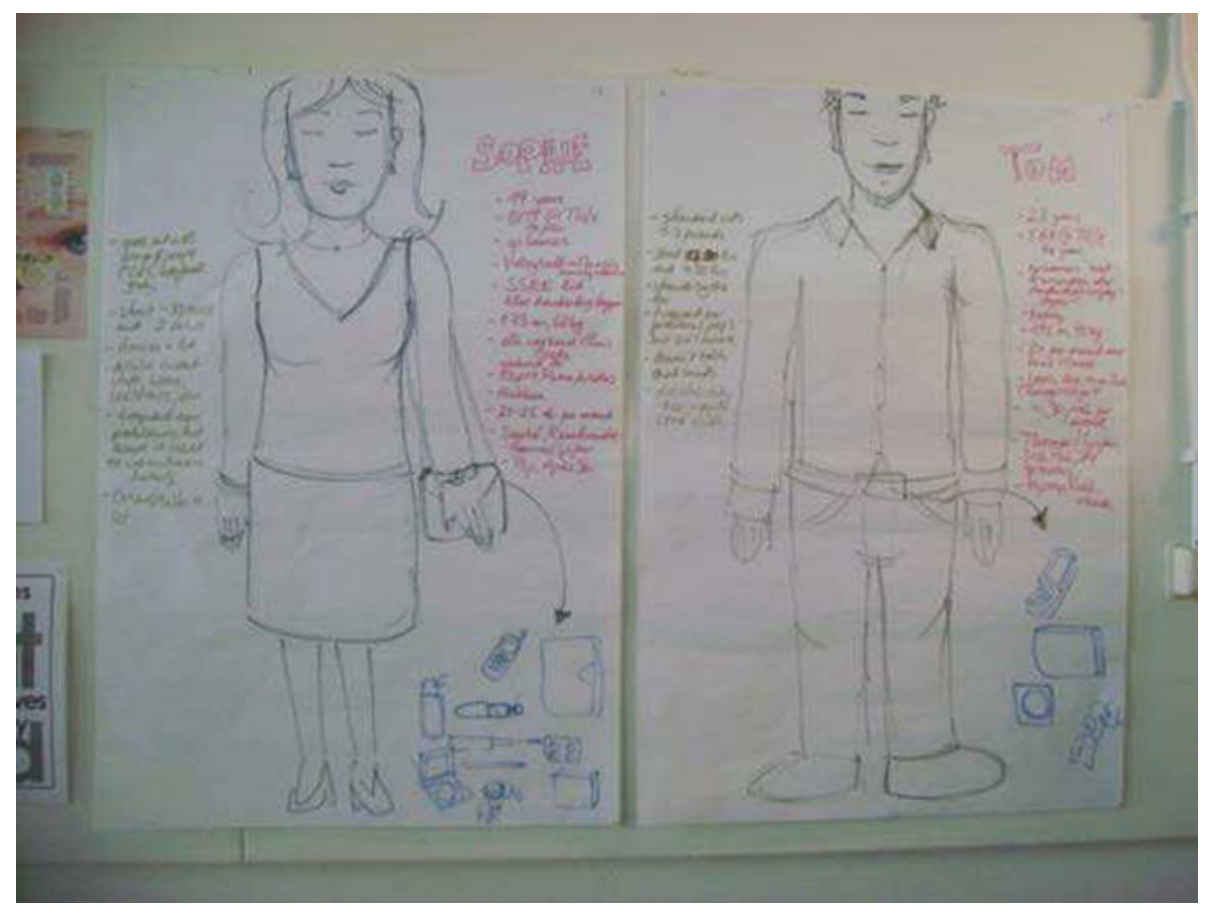

Fig. 6. Personas to share understanding, with annotations added by team members 


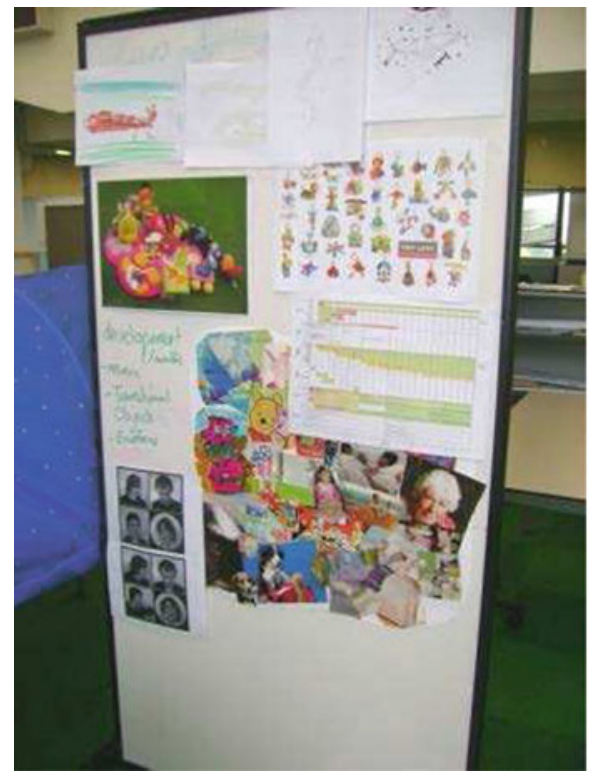

(a)

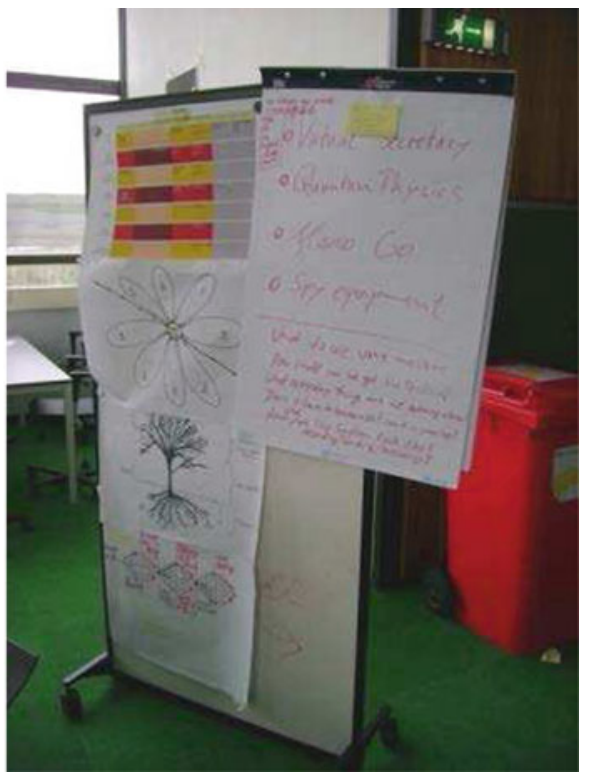

(b)

Fig. 7. Poster boards created to maintain shared awareness

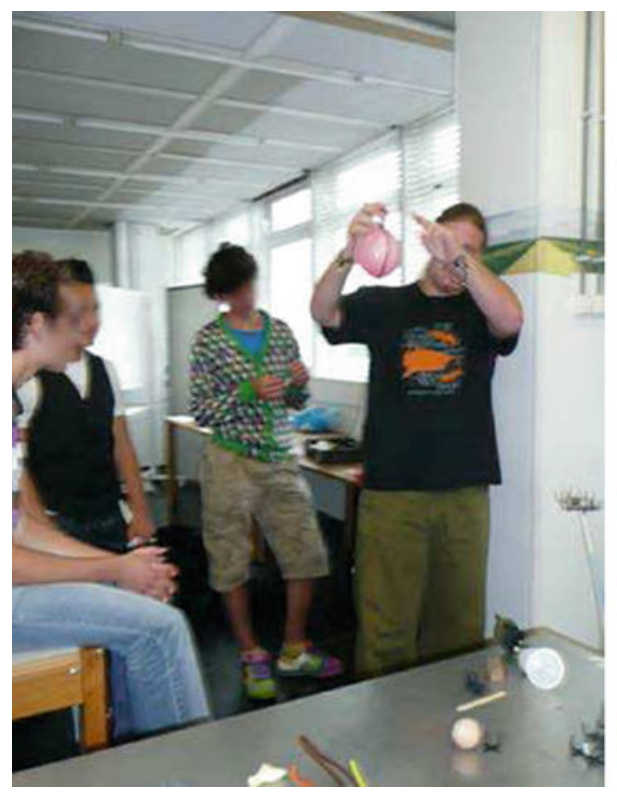

(a)

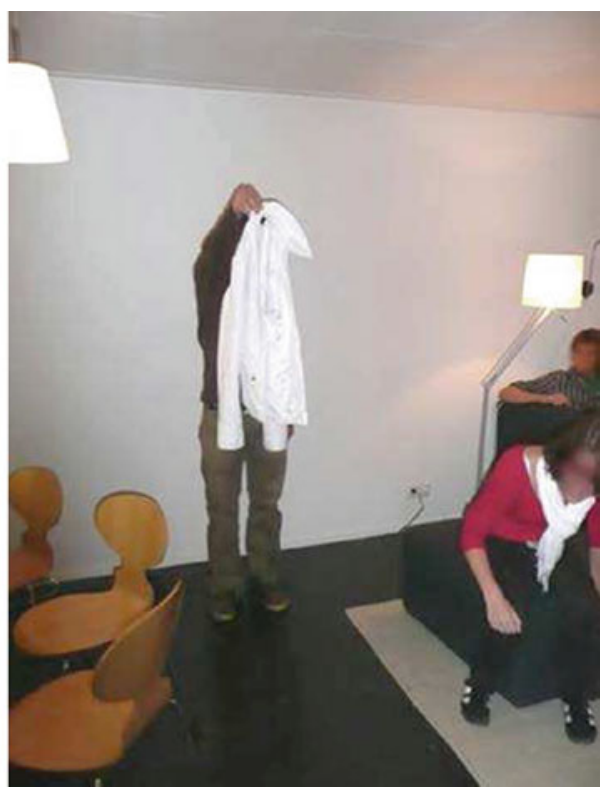

(b)

Fig. 8. Spontaneously developed performances to communicate meaning 


\section{Observation 3. Communication May Develop into Impromptu Performances}

On several occasions we identified communications that went far beyond single gestures, where a performance was staged to communicate the meaning of concepts or interaction with artifacts (Figs. 8(a) and (b)).

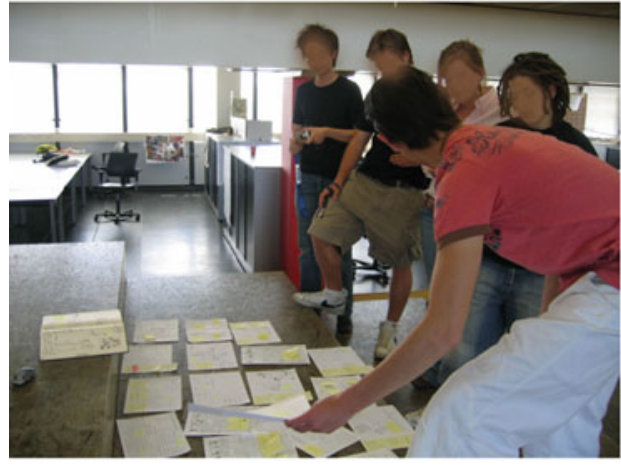

(a)

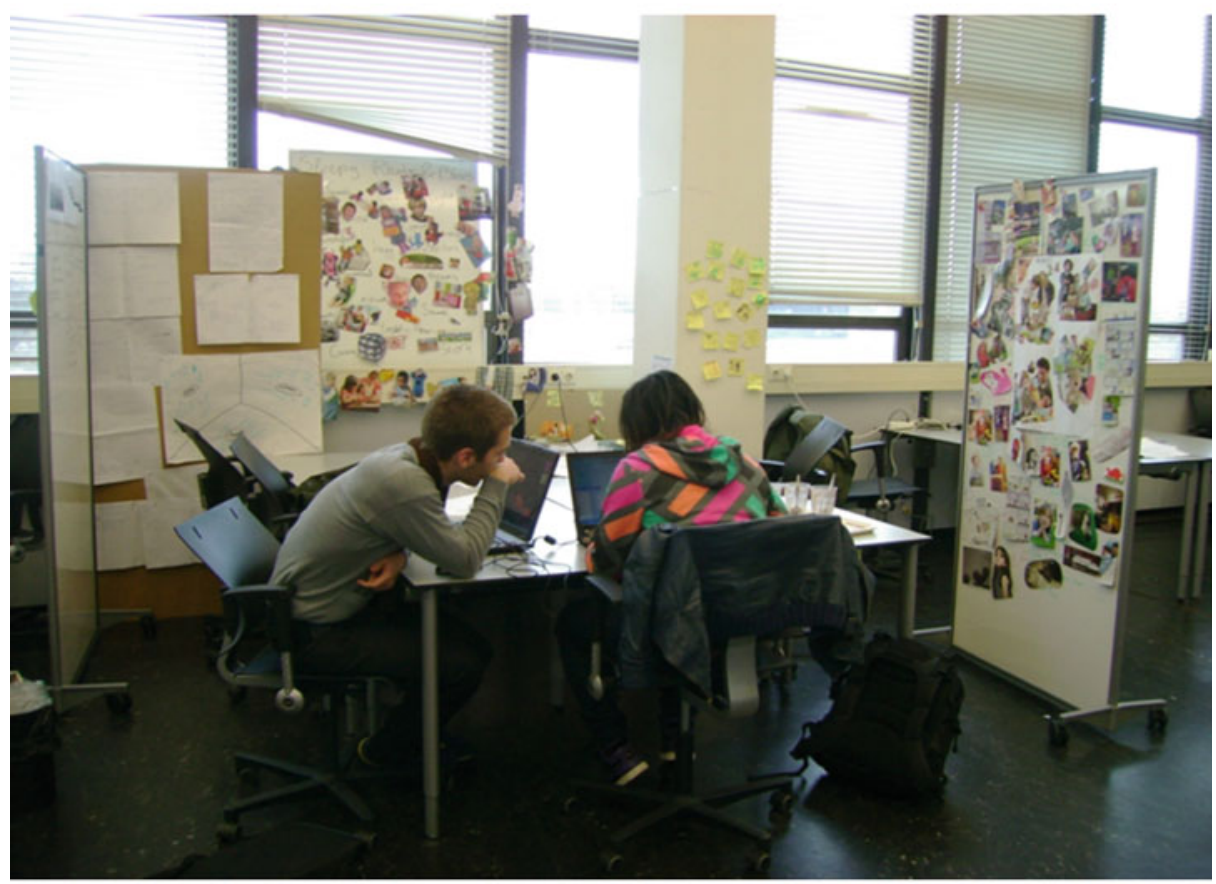

(c)

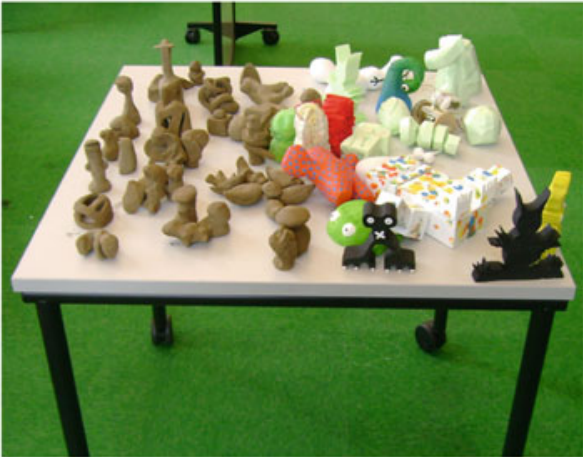

(b)

Fig. 9. Physical space used create structure; to understand development; and to share inspiration 


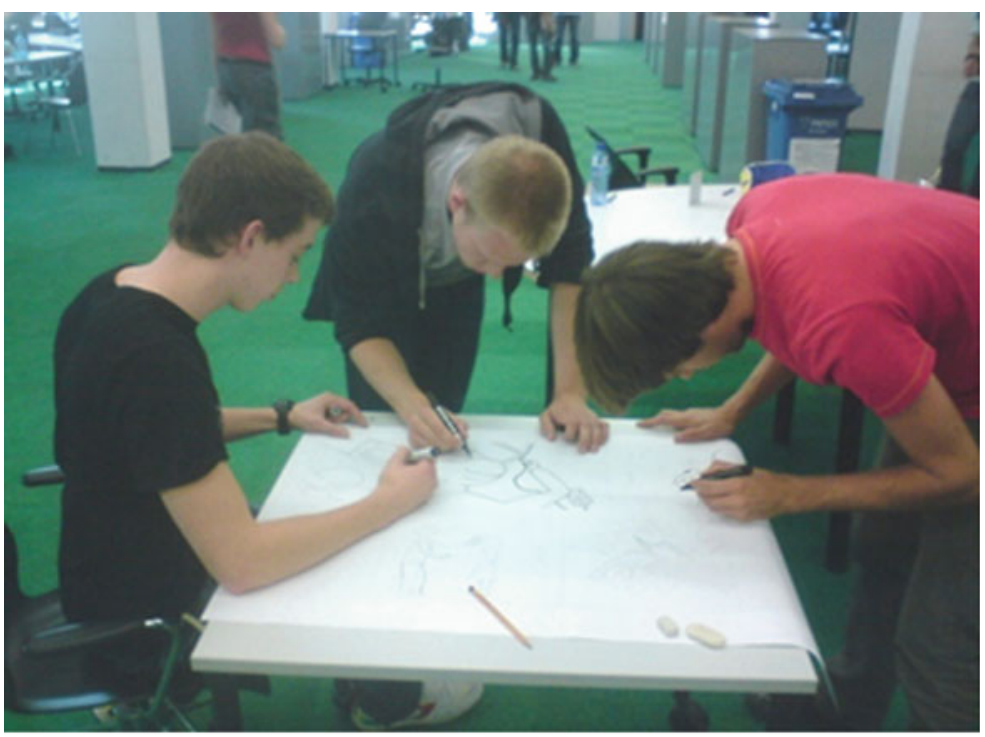

(a)

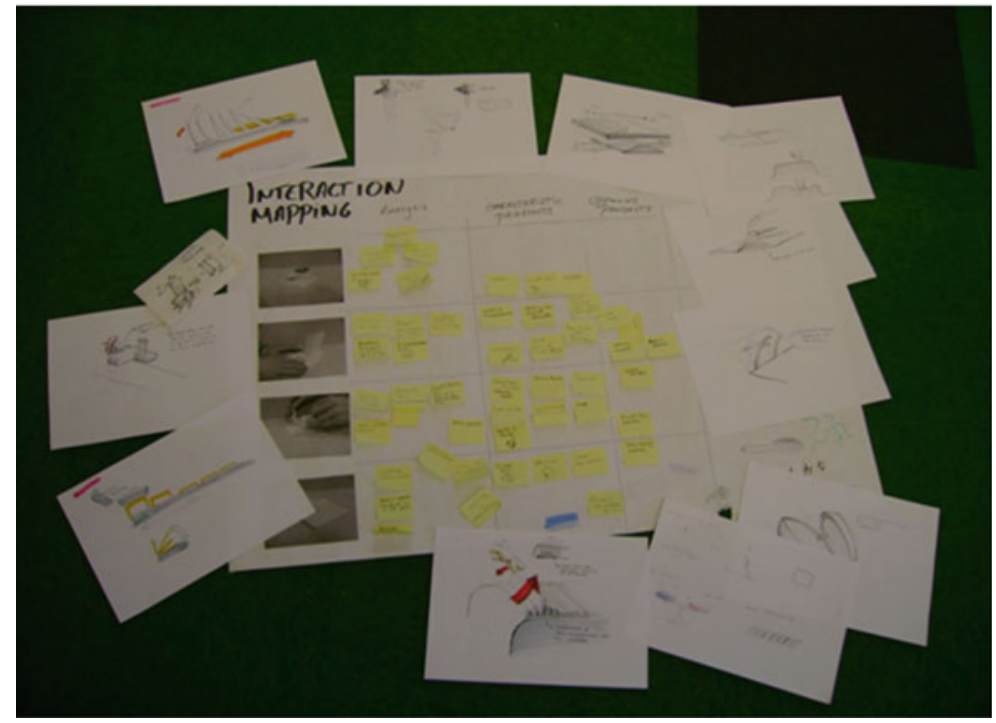

(b)

Fig. 10. Collaborative physical activities to develop shared understanding

\section{Observation 4. The Use of Physical Space}

Space is used to develop structure (Fig. 9(a)) by moving artifacts around; to compare and understand development (Fig. 9(b)) by observing physical configurations of representations of a developing concept, and to develop and share inspiration by moving around poster boards with representations (Fig. 9(c)). 


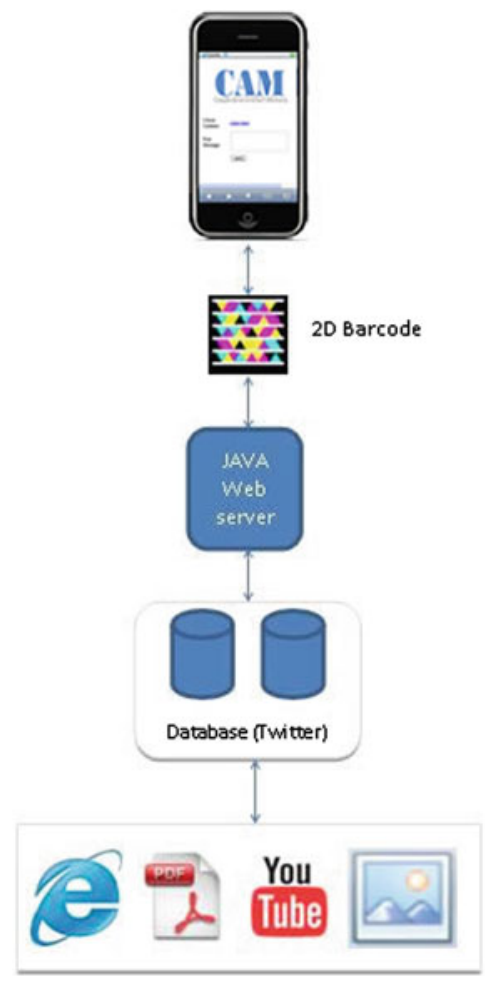

Fig. 11. Architecture of CAM

\section{Observation 5. Physicality of Collaboration}

Collaboration often is a physical activity, like group sketching (Fig. 10(a)) or adding and configuring annotations with sticky notes (Fig. 10(b)).

\section{Two Case Studies}

In the case studies reported next, we tried to support the design process, by on purpose providing a simple prototype concept that might physically as well as conceptually enrich the design ecology (case study 1) or by pointing to tools and techniques that in fact are supposed to trigger enrichment of the design ecology (case study 2). Case study 1 was performed in a Design faculty in a German University, including 3 design teams of 4 students each. Case study 2 was performed in an Italian University in the Faculty of Architecture and Design, with 5 teams of 3-4 students. In both cases, we never mentioned or hinted at the actual phenomena that we just discussed, we just provided a simple tool, or we just suggested our design students to consider the various tools for their design projects.

\section{Case Study 1: from Ethnography to Prototype Use}

Team work is characteristic for industrial design. Teams are often multidisciplinary. Collaboration on design is often not a purely verbal activity. State of the art ICT seems to provide intriguing tools for motivated teams. Based on our prior ethnographic work 


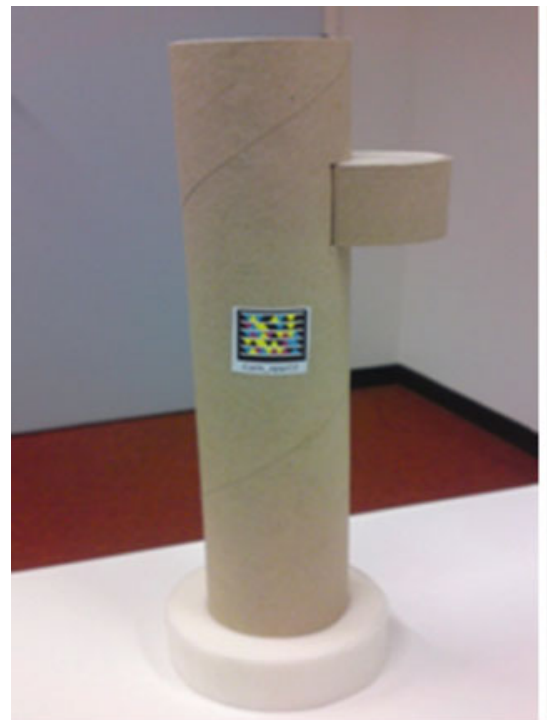

(a)

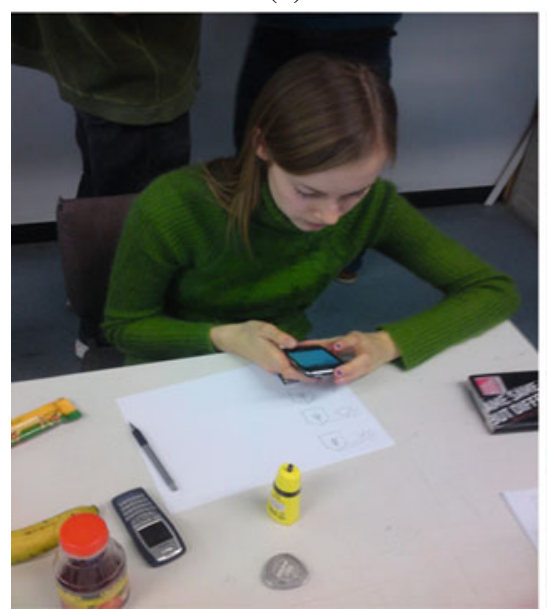

(c)

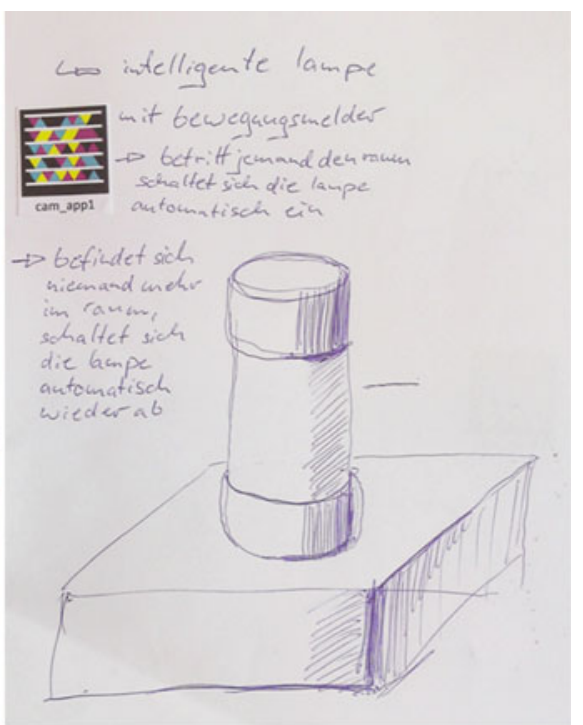

(b)

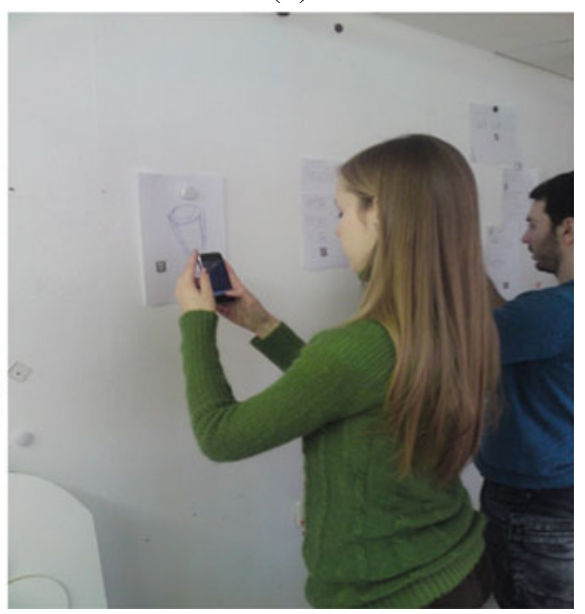

(d)

Fig. 12. Tagged mock-up and sketch; tweeting information to a tagged object; and reading the tweet log of a tagged object.

in design studios and with student design teams [7], we developed a simple tool, CAM (Fig. 11, from [8]).

CAM stands for "cooperative artifact memory". It is in fact a prototype that currently runs on an iPhone. Cam uses $2 \mathrm{D}$ barcodes that can be stuck to any physical object, whether 2D (e.g., anything on paper) or 3D (e.g. mockups and physical prototypes). See Figs. 12(a) and (b) where design team members decided to tag their design artifacts. The iPhone can be aimed at a tagged object and the barcode will be read. Each tagged object has its own digital profile on the internet, associated with a 


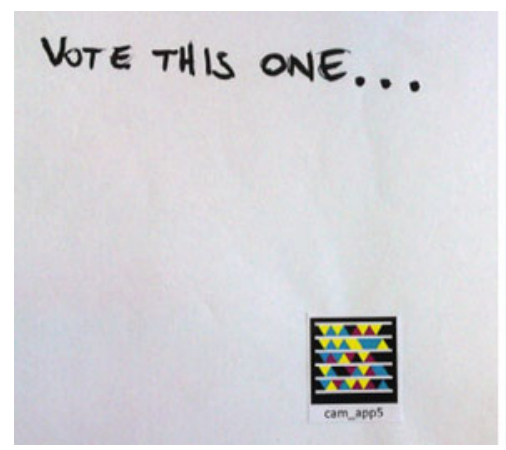

(a)

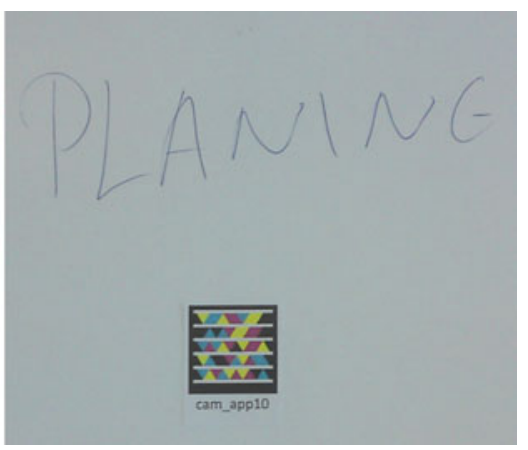

(b)

Fig. 13. CAM objects for decision making and planning

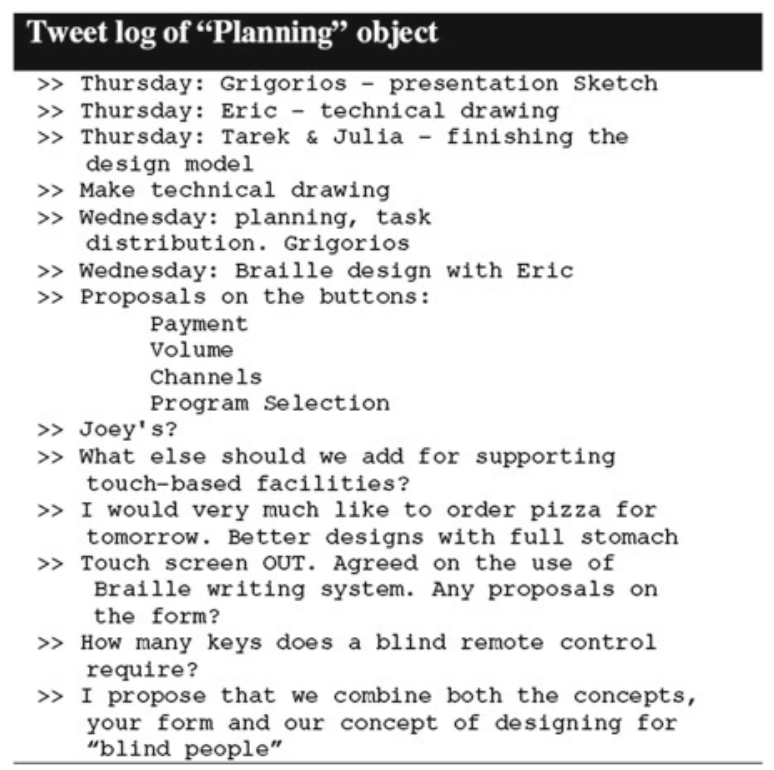

Fig. 14. Tweet log of "planning" object (translated from German. Time runs from below

twitter account. A JAVA web server has been developed to communicate through a Twitter API, to add information to any tagged object by sending a tweet to them (Fig. 12(c)), and to read the tweet log of each object (Fig. 12(d)).

We found three different teams of design students not only tagged and communicated to (a) 3-D mock-ups; (b) sketches, textual descriptions on paper, and combinations of these; but also (c) abstract references, like an empty sheet of paper only marked with, e.g., "vote on this", or "Planning" (Figs. 13(a) and (b)). Subsequently these became related to a history of tweets on votes and opinions about a proposed 


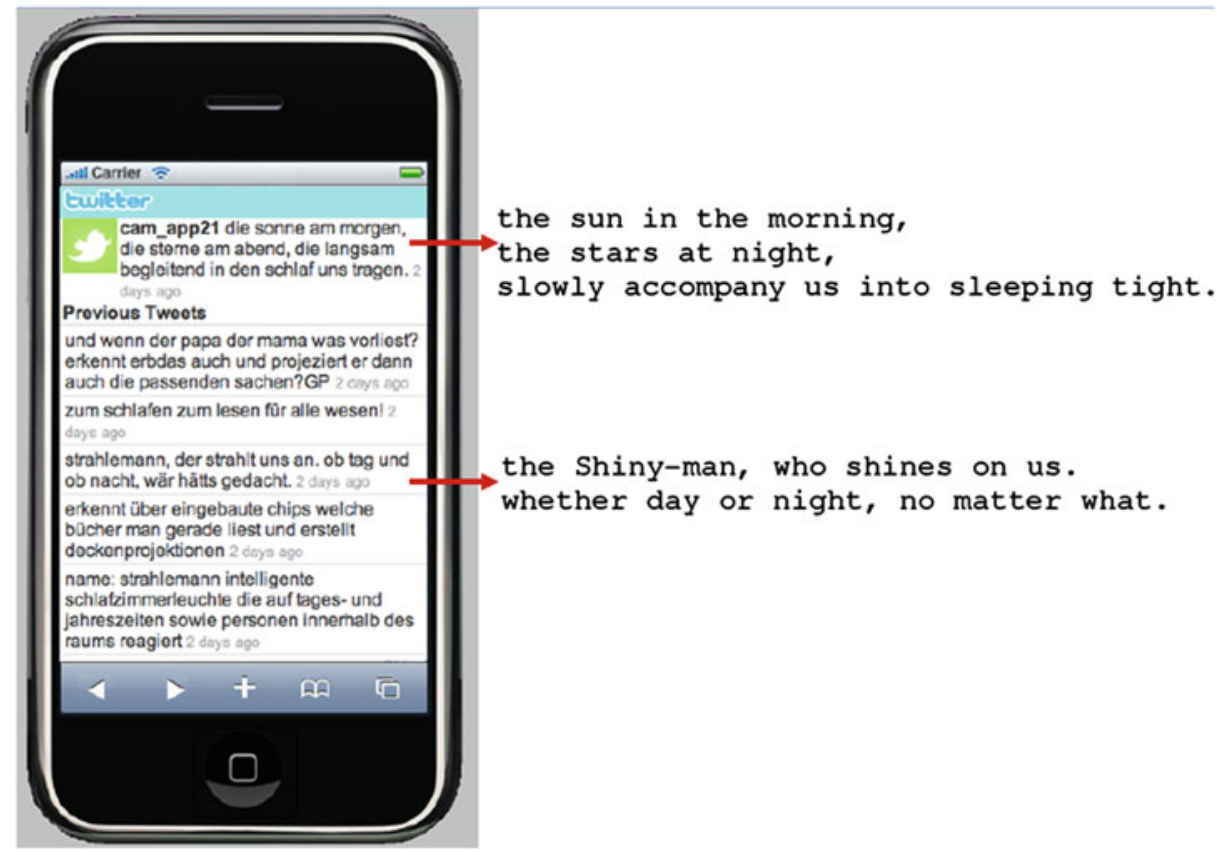

Fig. 15. Two short poems tweeted to a tagged sketch

design decision, resp., a history of tweets regarding a planned process and its actual deviations and updates (Fig. 14).

Another surprising way of using CAM was the opportunity to express emotions and aesthetics: e.g., a sketch for a night lamp triggered several "poems" by different "authors" (originally in German, Fig. 15).

In general, the tryout of CAM learned us that non-formal contributions to design were appreciated and we consider this a potential support for collaboration and shared creativity. Discovering new opportunities and functionality just "happened", though the tool seemed to systematically trigger certain new types of functionality in the design ecology, including abstract reference objects, and a stage for esthetical and emotional creations and performances.

\section{Case Study 2: Bootstrapping Service Design Techniques}

When developing a brand new course on service design, there were no course books available, and only a single repository for techniques [5]. Our students, worked in design teams for real clients to develop services with many different types of stakeholders outside the clients' business with clearly different corporate and geographical cultures (e.g., in tourism industry).

We pointed the students to Tassi's repository as well as to Hofstede and Hofstede's website [3] and to the Cultural Survival Kit [1], as well as to design documents from the UK Government and to our visual design pattern wizard [2]. We additionally introduced them to the design approach by Tassi [5]. 


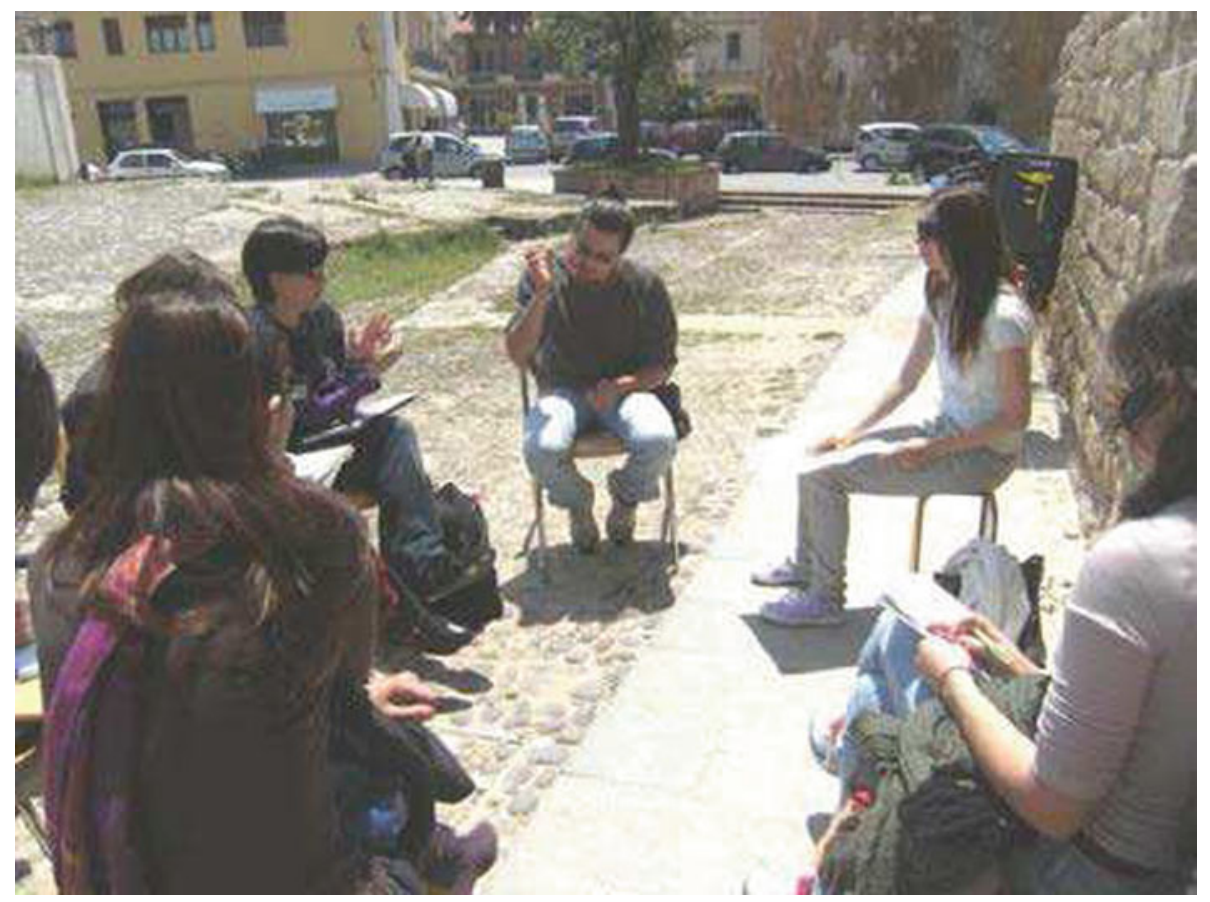

Fig. 16. Co-design with stakeholders

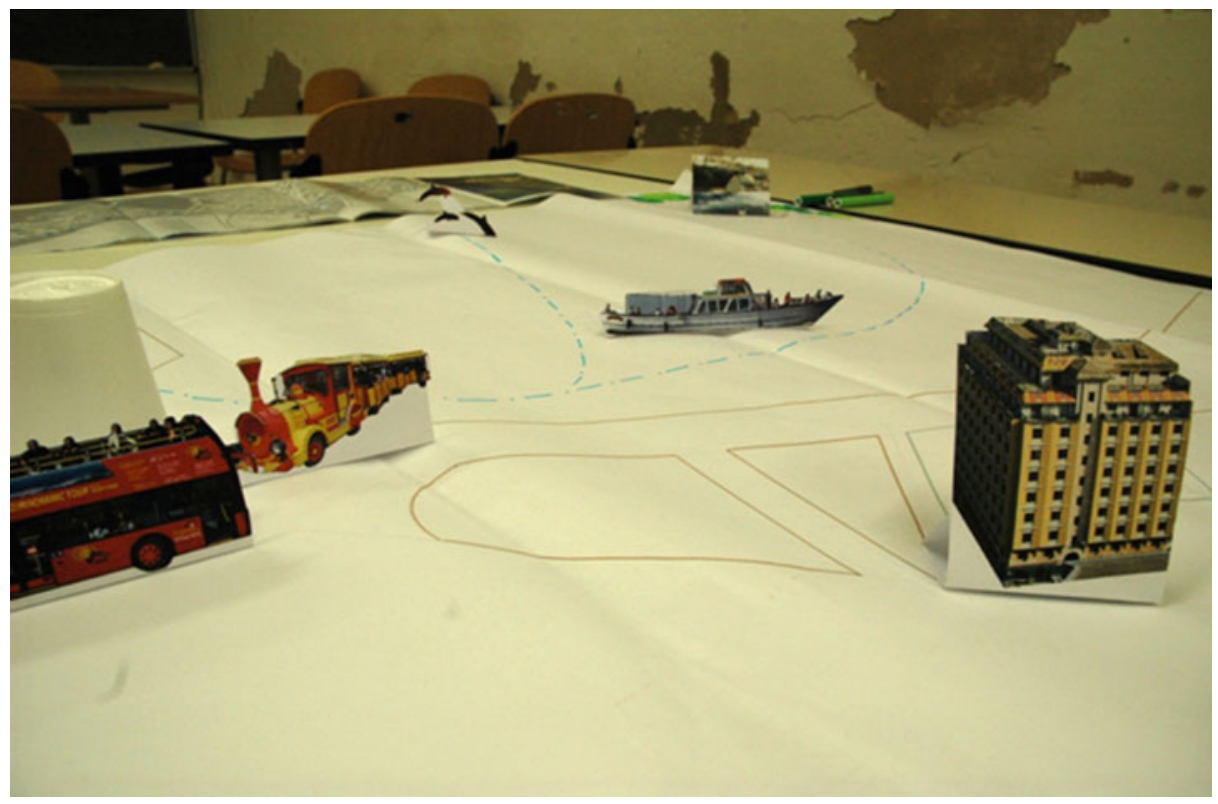

Fig. 17. 3-D mock up (rough prototype) presented to, and discussed with, various different stakeholders 
We asked our students to study these sources and to teach each other the different techniques and tools. During the design process we challenged them to decide for each phase which of the tools and techniques offered were relevant. The students' progressing projects showed how the various different non-formal techniques were applied to a co-design approach where different types of stakeholders (e.g., hotel owners, tourist information providers, and visitors; see Fig. 16) collaborated in generating ideas, e.g., group sketching. We also found non-formal techniques being applied for assessing concepts before any services were actually implemented, like rough prototyping with 3D mock ups (Fig. 17), unpredicted initiatives that were accepted and actually supported by the stakeholders.

\section{Conclusions}

Based on previous ethnographic studies we identified several phenomena of nonformal techniques applied in the early design phases of requirements elicitation, modeling and early assessment: the use of multiple types of communication, the relevance of design ecology, the possibility for impromptu creativity and performance, the use of physical space and the physicality of collaboration.

In two case studies with design students we provided two different potential supports for these phenomena, resp. a prototype system CAM to allow communication through design artifacts, and a set of techniques and tools that might be considered at will and taught by the design students to their peers.

The resulting design processes showed how these interventions spontaneously led to the students' choice of applying these facilities to support or create some of the afore mentioned phenomena.

We did not prove these interventions are the sole cause of the effects observed, but they certainly seem to help in providing a design ecology where the phenomena develop in a natural way, where students as well as stakeholders dare to embark on creative and multimodal behavior, communicate and collaborate on design meaning and create and maintain awareness of the process.

Our observations and case studies concerned University design student teams in several European countries (The Netherlands, Germany, Italy). Because we have experienced teaching Design in several other European countries (Spain, Romania, Belgium) we dare expect the phenomena we observed during ethnography and case studies) are typical for European student design teams. We are currently teaching design in a University in China, which will be an opportunity to validate our understanding for a rather different cultural context. Still, we should also validate our analysis for design outside of the University situation. Ethnographic observations, as well as case studies in industrial design practice will have to be a next step.

\section{References}

1. Cultural Survival Kit http://wiki.morevm.org/index.php/Main_Page (2011)

2. de Moel N., van der Veer G.C.: Design pattern based decision support. In: Dittmar, A., Forbrig, P. (eds.) Designing Collaborative Activities - Proceedings of ECCE 2011. ACM Digital Library, pp. 93-96 (2011) 
3. Hofstede G., Hofstede G.J.: www.geerthofstede.nl (2011)

4. Sommerville, I.: Integrated requirements engineering: a tutorial. IEEE Softw. 22(12), 16-23 (2005)

5. Tassi R.: Servicedesigntools. www.servicedesigntools.org/repository (2009). Accessed June 2010

6. Van Welie, M., van der Veer, G.C.: Groupware task analysis. In: Hollnagel, E. (ed.) Handbook of Cognitive Task Design, pp. 447-476. Erlbaum, Inc., Hillsdale (2003)

7. Vyas, D.M., Heylen, D.K.J., Nijholt, A., van der Veer, G.C.: Collaborative practices that support creativity in design. In: Proceedings of the Eleventh European Conference on Computer-Supported Cooperative Work - ECSCW. pp. 151-170, Springer, Berlin (2009)

8. Vyas, D.M., Nijholt, A., Heylen, D.K.J., Kroener A., van der Veer G.C.: Remarkable objects: supporting collaboration in a creative environment. In: Bardram, J. (ed.) 12th ACM International Conference on Ubiquitous Computing, pp. 1-4. ACM, New York (2010) 